\title{
ANALISIS LOGAM BERAT TIMBAL (Pb) PADA AKAR MANGROVE DI DESA BAHOWO DAN DESA TALAWAAN BAJO KECAMATAN TONGKAINA
}

\author{
(Analisis of Heavy Methal Lead (Pb) in Mangrove Roots in Bawoho Village and \\ Talawaan Bajo Village, Tongkaina District)
}

\section{Troy Hendro Sanadi ${ }^{1 *}$, Joshian N.W. Schaduw ${ }^{1}$, Sandra O. Tilaar ${ }^{1}$, Desy Mantiri ${ }^{1}$, Robert Bara ${ }^{1}$, Wilmy Pelle ${ }^{1}$}

1. Program Studi IImu Kelautan, Fakultas Perikanan dan IImu Kelautan, Universitas Sam Ratulangi, Manado.

2. Program Studi Manajemen Sumberdaya Perairan, Fakultas Perikanan dan IImu Kelautan, Universitas Sam Ratulangi, Manado.

*e-mail : sanaditroy@gmail.com

Mangroves are plant species that have biofilter capabilities; i.e. the ability to filter, bind and trap pollution in the wild nature or commonly referred to as hyperaccumulator plants. It's the ability to bind and trap excess sediments, household waste and store heavy metals in the roots, stems and leaves that play an important role and help neutralize the heavy metal pollutants such as lead $(\mathrm{Pb})$ that penetrate the water and improve water quality. The objective of this research is to determine the absorption capacity of mangroves in absorbing $\mathrm{Pb}$ heavy metals in mangrove roots in the areas of Bahowo Coast and the Bajo Talawaan Coast. The samples, which had been obtained, were analyzed using Atomic Absorption Spectrophotometry (AAS) then data processing was carried out. The findings, obtained from this research, found that the ability of mangroves to absorb heavy metals in each species has a different absorption ability. The analysis results of root samples, which were carried out using AAS tools, found that Avicennia marina mangrove has the ability to absorb $\mathrm{Pb}$ heavy metals better than Soneratia alba species. Based on the analysis results, it was found that the Bahowo area has sufficient $\mathrm{Pb}$ heavy metal concentrations and is still below the quality standard of plants.

Keywords: Heavy metals; Mangroves; Bahowo; Talawaan

Mangrove merupakan jenis tumbuhan yang memiliki kemampuan biofilter, yaitu kemampuan untuk menyaring, mengikat dan memerangkap polusi di alam bebas atau biasa disebut sebagai Tumbuhan Hiperakumulator. Kemampuan mengikat dan memerangkap berupa kelebihan sedimen, limbah buangan rumah tangga dan menyimpan logam berat pada akar, batang dan daunnya berperan penting dan membantu dalam menetralisir masuknya sumber pencemar logam berat seperti timbal $(\mathrm{Pb})$ yang masuk ke dalam perairan dan meningkatkan kualitas air. Tujuan dari penelitian ini adalah untuk mengetahui kemampuan daya serap Tumbuhan mangrove dalam menyerap logam berat $\mathrm{Pb}$ pada akar mangrove di daerah Pesisir Bahowo dan Pesisir Talawaan Bajo. Sampel yang telah diperoleh kemudian di analisis mmengunakan Atomic Absorbtion Spectrophotometry (AAS) dan dilakukan pengolahan data. Hasil yang diperoleh dari penelitian ini menemukan bahwa kemampuan mangrove dalam menyerap logam berat setiap spesiesnya memiliki kemampuan menyerap yang berbeda-beda. Hasil dari analasis sampel akar yang dilakukan mengunakan alat AAS, menemukan bahwa mangrove jenis Avicennia marina memiliki kemampuan menyerap logam berat $\mathrm{Pb}$ lebih baik dari jenis Soneratia alba. Dari hasil analisis ditemukan pada daerah Bahowo memiliki konsentrasi logam berat $\mathrm{Pb}$ yang cukup yang masih berada dibawah standar baku mutu pada tumbuhan.

Kata kunci :Logam berat; Mangrove; Bahowo; Talawaan 


\section{PENDAHULUAN}

Peningkatan kualitas hidup
manusia untuk mendapatkan
kenyamanan dan kesejatrahan hidup
yang baik $\quad$ mengakibatkan meningkatnya aktivitas manusia dalam bidang industri dan penambangan yang banyak menghasilkan logam berat. Masuknya bahan pencemar ke dalam lingkungan yang semakin tinggi mengakibatkan rusaknya lingkungan. Suatu lingkungan dikatakan tercemar oleh logam berat apabila kandungan logam berat pada lingkungan atau ekosistem tersebut telah melebihi nilai baku mutu lingkungan yang ditetapkan untuk kandungan logam berat. Logam berat $\mathrm{Pb}$ merupakan logam berat yang termasuk ke dalam jenis logam berat yang berbahaya bagi manusia jika ikut terkonsumsi lewat makanan atau minuman yang dikonsumsi, logam berat $\mathrm{Pb}$ juga sangat berbahaya jika masuk kedalam lingkungan secara berlebihan karena dapat mencemari dan merusak lingkungan, dimana logam berat berbahaya bagi biota dan tumbuhan dalam suatu lingkungan (Setiabudi, 2005).

\begin{tabular}{llr}
\multicolumn{2}{c}{ Bioremediasi } & $\begin{array}{r}\text { merupakan } \\
\text { pengembangan dari }\end{array}$ \\
bioteknologi lingkungan dengan \\
memanfaatkan proses biologi dalam \\
mengendalikan pencemaran atau
\end{tabular} polutan. bioremediasi merujuk pada penggunaan secara produktif proses biodegradatif untuk menghilangkan atau mendetoksi polutan (biasanya kontaminan tanah, air dan sedimen) yang mencemari lingkungan dan mengancam kesehatan masyarakat. Jadi bioremediasi adalah salah satu teknologi alternatif untuk mengatasi masalah lingkungan dengan memanfaatkan bantuan mikroorganisme. Penggunaan tumbuhan ini biasa dikenal dengan istilah fitoremediasi (Crawford and Crawford, 1996).

Jenis-jenis tanaman yang dapat melakukan remediasi disebut dengan tanaman hiperakumulator yaitu tumbuhan yang mampu mentranslokasikan unsur-unsur tertentu dengan konsentrasi tinggi ke rendah tanpa membuat tanaman tersebut tumbuh dengan tidak normal dalam arti kata tidak kerdil serta tidak mengalami fitotoksisitas. Mangrove masuk dalam tanaman hiperakular karena berfungsi sebagai agen bioremidiasi alami karena secara alami mangrove dapat menyerap kandungan logam berat di alam dan fungsi ini disebut sebagai biosorbsi (Hastuti, et al., 2013). Mangrove juga memiliki kemampuan yang di sebut biofilter, yaitu kemampuan untuk menyaring, mengikat dan memerangkap polusi di alam bebas berupa kelebian sedimen, sampah dan limbah buangan rumah tangga lainnya. Fungsi ini berperan dalam meningkatkan kualitas air (Gunarto, 2004).

Logam berat yang masuk kedalam lingkungan pada konsentrasi tertentu mampu dinetralisir oleh tumbuhan Hiperakumulator salah satunya tumbuhan mangrove. Mangrove menjadi salah satu tumbuhan yang dapat digunakan atau dikembangkan untuk menangani masalah pencemaran logam berat pada lingkungan. Oleh sebab itu fokus dari penelitian yang dilakukan di desa Bahowo dan Talawaan bajo, kecamatan Tongkaina, dilakukan untuk menganalisis kemampuan mangrove menyerap logam berat.

Hutan mangrove adalah sebutan umum yang digunakan untuk menggambarkan suatu komunitas pantai tropik yang didominasi oleh beberapa species pohon yang khas atau semak-semak yang mempunyai kemampuan untuk tumbuh dalam perairan asin (Nybakken, 1988). Hutan mangrove disebut juga "Coastal Woodland" (hutan pantai) atau "Tidal Forest" (hutan surut)/hutan bakau, yang merupakan formasi tumbuhan litoral yang karakteristiknya terdapat di daerah tropika (Saenger, 1983). Menurut Schaduw (2015), Indonesia memiliki luas ekosistem 
mangrove terbesar di dunia yaitu sebesar $19 \%$ dari luas ekosistem mangrove di dunia. Hutan mangrove di daerah TNB sangat luas (1528,29 ha) yaitu sekitar $10 \%$ dari luas total hutan mangrove di Sulawesi Utara. Komunitas mangrove di TNB termasuk komunitas yang tua di Asia Tenggara karena masih ditemukan pohon mangrove yang berukuran besar dengan diameter diatas $1,5 \mathrm{~m}$ yang jarang ditemukan di tempat yang lain. Menurut Dahuri (2003), ekosistem mangrove adalah ekosistem yang tergolong tidak dinamis karena ekosistem hutan mangrove tidak dapat terus berkembang dan bertumbuh sesuai dengan perubahan tempat tumbuhnya, ekositem mangrove sangat sulit beradaptasi dengan perubahan lingkungan yang tercemar. Hutan mangrove tergolong labil karena mudah sekali rusak dan sulit untuk pulih kembali.

Mangrove berperan sebagai penampungan terakhir bagi limbah dari aktivitas perkotaan yang terbawa oleh aliran sungai ke muara sungai (Mulyadi, et al, 2009). Limbah padat dan cair yang terlarut dalam air sungai terbawa arus menuju muara sungai dan laut lepas. Kawasan hutan mangrove akan menjadi daerah penumpukan limbah, terutama jika polutan yang masuk ke dalam lingkungan estuari melampaui kemampuan pemurnian alami oleh air. Mangrove merupakan tumbuhan tingkat tinggi di kawasan pantai yang dapat berfungsi untuk menyerap bahan-bahan organik dan non-organik sehingga dapat dijadikan bioindikator logam berat (MacFarlane, et al., 2000). Mangrove memiliki kemampuan untuk menyerap dan menyimpan logam berat dalam jaringan tubuh seperti daun, batang dan akar yang terbawa di dalam sedimen, sebagian sumber hara tersebut dibutuhkan untuk melakukan proses-proses metabolisme.

Sebuah studi mengenai efek dari pembuangan limbah pada komunitas mangrove di Darwin Australia mengatakan bahwa pohon mangrove memiliki kapasitas tinggi untuk menerima muatan limbah tanpa menderita kerusakan pada pertumbuhan mangrove. Penelitian mengenai akumulasi dan distribusi logam berat pada mangrove yang hasilnya menyatakan bahwa kandungan logam berat lebih banyak ditemukan di perakaran. Baik dalam sedimen maupun tanaman, konsentrasi logam berat meningkat sesuai peningkatan jumlah air dari pembuangan. Kemampuan untuk menahan logam berat tergantung dari usia tanaman dan produksi biomassa (Tam, 1997).

Penggunaan tumbuhan atau pohon untuk menyisihkan atau menetralkan kontaminan, seperti yang berada dalam tanah atau air yang tercemar (Bahri, 2010). Istilah fitoremediasi sendiri merupakan pengembangan dari konsep bioremediasi secara umum. Dalam istilah bioremediasi, senyawa kontaminan yang di sisikan atau dinetralkan dapat berupa senyawa berbahaya. Senyawa berbahaya tersebut merupakan senyawa target yang mungkin atau tidak mungkin dapat menjadi bagian substrat tumbuhan. Keberhasilan fitoremediasi dikendalikan oleh adanya sumber energy yang sesuai, sistem donor akseptor electron dan nutrient (Bahri, 2010).

\section{METODE PENELITIAN}

\section{Tempat dan Waktu Penelitian}

Pelaksanaan penelitian dilakukan pada bulan oktober-november, lokasi penelitian di lakukan dengan dua titik pengambilan sampel yaitu di desa Bahowo dan desa Talawaan Bajo Kecamatan Tongkaina. Lokasi pengambilan sampel dapat dilihat pada Gambar 1. 


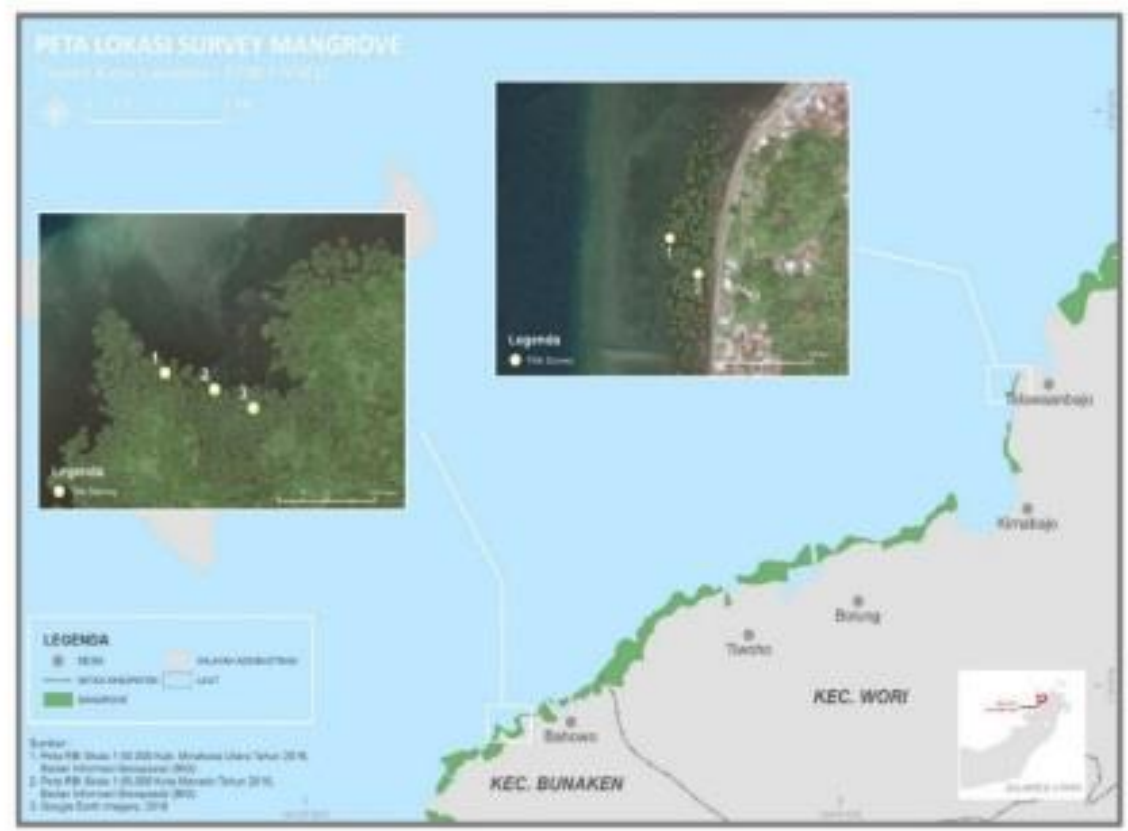

Gambar 1. Peta Lokasi Penelitian.

Sebelum dilakukan proses pengambilan sampel dilapangan dilakukan pengamatan terlebih dahulu spesies apa yang tumbuh pada keduan lokasi. Setelah pengamatan spesies, dilakukan pengambilan sampel akar mangrove dari kedua lokasi dari jenis spesies yang sama. Selanjutnya analisis sampel akan dilaksanakan di Laboratorium Balai Karantina Ikan Manado, Sulawesi Utara.

\section{Alat dan Bahan}

Penelitian ini dilaksanakan dengan menggunakan seperangkat alat dan bahan. Alat dan bahan penelitian ini dapat dilihat pada Tabel 1 .

\section{Prosedur Pengambilan Sampel}

Prosedur pengambilan sampel akar mangrove dan prosedur analis logam berat di laboratoriun dapat dilihat pada Gambar 2 dan 3.

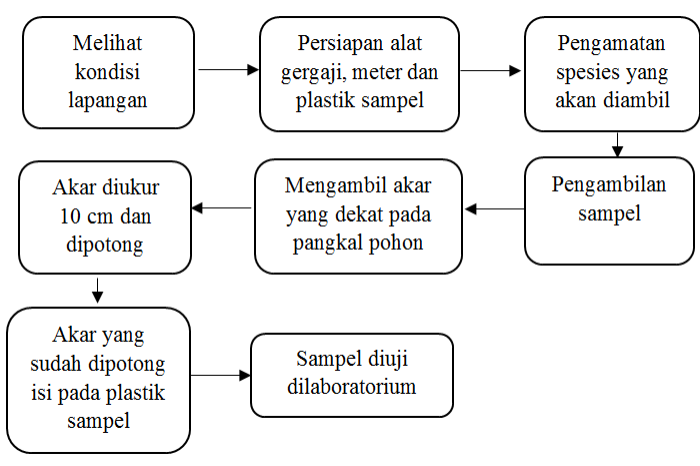

Gambar 2. Prosedur pengambilan sampel.

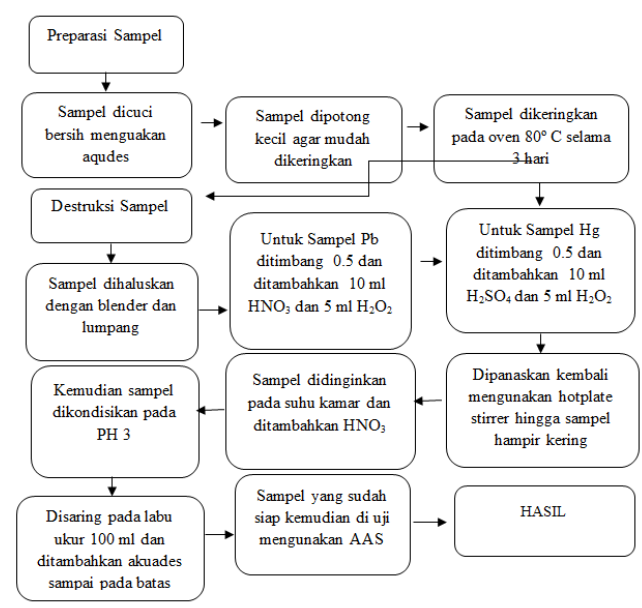

Gambar 3. Metode analisis sampel. 
Tabel 1 . Daftar alat dan bahan beserta kegunaannya.

\begin{tabular}{|c|c|c|}
\hline No. & Alat/Bahan & Kegunaan \\
\hline 1. & Gergaji & $\begin{array}{l}\text { Membantu proses pemotongan sampel saat } \\
\text { pengambilan akar di lapangan }\end{array}$ \\
\hline 2. & Plastic sample & $\begin{array}{l}\text { Mengisi sample pada saat pengambilan di } \\
\text { lapangan }\end{array}$ \\
\hline 3. & Aquades & Digunakan pada saat proses pembersihan sampel \\
\hline 4. & Sampel akar mangrove & Sampel akar Mangrove yang akan di uji \\
\hline 5. & Pisau & $\begin{array}{l}\text { Membantu saat proses pemotongan sample ke } \\
\text { ukuran yang lebih kecil }\end{array}$ \\
\hline 6. & Cawan Porcelin & Sebagai wadah sampel saat proses pengeringan \\
\hline 7. & Oven & Digunakan saat proses pengeringan sampel \\
\hline 8. & Blender & Membantu dalam proses penghalusan sampel \\
\hline 9. & Erlenmeyer & $\begin{array}{l}\text { Sebagai wadah pencampuran bahan-bahan kimia } \\
\text { yang digunakan }\end{array}$ \\
\hline 10. & Gelas beker & $\begin{array}{l}\text { Sebagai wadah cairan kimia yang digunakan pada } \\
\text { saat proses destruksi sampel }\end{array}$ \\
\hline 11. & Gelas ukur & Mengukur banyaknya pelarut yang akan digunakan \\
\hline 12. & Corong gelas & Sebagai alat bantu saat proses penyaringan bahan \\
\hline 13. & Glove & Melindungi tangan dari bahan kimia dan bakteri \\
\hline 14. & $\begin{array}{l}\text { Pipet ukur 50ml dan } \\
100 \mathrm{ml}\end{array}$ & $\begin{array}{l}\text { Mengambil cairan bahan kimia atau sampe yang } \\
\text { digunakan. }\end{array}$ \\
\hline 15. & Indikator universal & $\begin{array}{l}\text { Mengukur tingkat keasaman bahan yang } \\
\text { digunakan saat percampuran. }\end{array}$ \\
\hline 16. & Kertas label & $\begin{array}{l}\text { Menandai sampel dan cawan sampel agar mudah } \\
\text { di control. }\end{array}$ \\
\hline 17. & Kertas saring & Menyaring ekstrak sampel sebelum di uji AAS. \\
\hline 18. & Timbangan analitik & Menimbang sampel untuk di ekstrasi. \\
\hline 19. & Hotplate stire & $\begin{array}{l}\text { Sebagai tempat pemanas sample } \\
\text { percampuran dengan bahan kimia yang } \\
\text { digunakan. }\end{array}$ \\
\hline 20. & Pipet tetes & $\begin{array}{l}\text { Sebagai pengambilan cairan kimia yang } \\
\text { digunakan. }\end{array}$ \\
\hline 21. & Masker & Menghindari uap bahan kimia yang berbahaya. \\
\hline 22. & Asam nitrat encer & Digunakan pada saat proses destruksi sampel. \\
\hline $\begin{array}{l}23 . \\
24 .\end{array}$ & $\begin{array}{l}\text { Hidrogen peroxide } \\
\text { Lumpang }\end{array}$ & $\begin{array}{l}\text { Digunakan pada saat proses destruksi sampel. } \\
\text { Menghaluskan Sampel }\end{array}$ \\
\hline 25. & Labu takar & $\begin{array}{l}\text { Mengisi dan menyimpan sampel yang siap di } \\
\text { analisis mengunakan alat AAS. }\end{array}$ \\
\hline 25. & Alat AAS & $\begin{array}{l}\text { Sebagai alat pengujian logam berat pada sampel } \\
\text { yang di buat }\end{array}$ \\
\hline
\end{tabular}




\section{Analisis Sampel di Laboratorium}

Sampel akar mangrove yang sudah diambil kemudian dicuci bersih mengunakan aquades kemudian sampel yang te lah dibersihkan dipotong-potong mengunakan pisau ke ukuran yang lebih kecil guna mempermudah dalam proses pengeringan sampel untuk menghilangkan kandungn air dalam sampel. Selanjutnya sampel yang sudah dipotong ditaruh pada cawan porceline dan dioven dengan suhu 80 ${ }^{\circ} \mathrm{C}$ selama 3 hari.

\section{Destruksi Sampel}

Sampel akar yang telah dikeringkan dalam oven kemudian di dinginkan lalu masing-masing dihaluskan dengan blender dan lumpang hinga halus. Setelah sampel di haluskan sampel ditimbang masingmasing seberat $0,5 \mathrm{gr}$ pada wadah porceline, kemudian dalam pengujian $\mathrm{Pb}$ ditambahkan $10 \mathrm{ml} \mathrm{HNO}_{\mathrm{p}}$ dan $5 \mathrm{ml}$ $\mathrm{H}_{2} \mathrm{O}_{2}$, selanjutnya dipanaskan di atas hot plate sampai hampir kering. Sampel kemudian di diamkan pada suhu kamar selanjutnya ditambahkan $\mathrm{HNO}_{3}$ encer dan $\mathrm{H}_{2} \mathrm{SO}_{4}$ di kondisikkan pada $\mathrm{pH} 3$, di saring dan di masukkan kedalam labu takar $100 \mathrm{ml}$, ditambahkan aquades sampai tanda batas.

\section{Proses Ekstrasi}

Sampel akar mangrove yang sudah melalui proses ekstrasi selama 4 hari kemudian sampel di isi pada labu takar leher panjang $100 \mathrm{ml}$ kemudian diberi lebel pertiap sampel agar mudah di lihat dan tidak tertukar pada saat pengujian AAS. Setelah sampel di isi dan diberi label kemudian sampel di simpan pada suhu kamar. Proser selanjutnya sampel yang di simpan pada suhu kamar kemudian di lanjutkan dengan pemeriksaan kadar logam berat $\mathrm{Pb}$ pada sampel akar mangrove mengunakan alat AAS untuk melihat kadar logam berat yang ada pada akar mangrove.

\section{Pengujian AAS}

Sampel akar mangrove yang telah siap untuk penujian kemudian dipisahkan antara sampel $\mathrm{Pb}$ dan sampel $\mathrm{Hg}$. Proses pengujian mengunakan AAS untuk kedua sampel dilakukan terpisah. Sampel $\mathrm{Pb}$ yang diuji mengunakan Teknik pembakaran suhu tinggi ( graphit Furnace) dimana sampel diuji mengukanan pembakaran suhu tinggi untuk pemecahan partikel dan pada saat pemecahan partikel lansung ditangkap dan dibaca kandungan $\mathrm{Pb}$ oleh lampu elemen.

\section{Prosedur Analisis Mengunakan Alat AAS}

Pengujian sampel mengunakan AAS dibagi menjadi beberapa tahap yaitu:

a. Penyalaan dan seting alat:

1) Menyalakan alat AAS

2) Melakukan optimasi agar kerja alat stabil

3) Pembuatan metode

4) Menentukan Panjang penyinaran

5) Seting layar kerja

6) Pemilihan lampu elemen

b. Pembuatan reduktan

Reduktan dibuat dari 1 liter $\mathrm{NaOH}$ $0,5 \%+0.2$ gr NaBh 4 . Reduktan berfungsi mereduksi senyawasenyawa selain target logam dengan mereduksi secara kimiawi.

c. Membuat larutan pelindung $\mathrm{Hcl} 3 \%$, dibuat dari $\mathrm{HCl} 37 \%$ diambil $87 \mathrm{ml}$ dan di isi pada labu ukur 1 liter, fungsi dari larutan pelindung saat analisis dijalankan.

d. Untuk pengujian logam berat $\mathrm{Pb}$ digunakan Teknik (furnace) pembakaran suhu tinggi)

e. Sampel yang sudah ada siap untuk diuji.

\section{Analisis Data}

Sampel akar mangrove yang telah diuji kandungan logam berat $\mathrm{Pb}$ selanjutnya dilakukan analisis data 
mengunakan program komputer exel. Analisis data yang dilakukan bertujuan untuk mencari nilai rata-rata kemampuan daya serapan logam berat $\mathrm{Pb}$ setiap spesiesnya dan penyerapan logam berat pada kedua stasiun pengambilan sampel.

\section{HASIL DAN PEMBAHASAN}

\section{Hasil Identifikasi Mangrove}

Dari hasil identifikasi mangrove menunjukan bahwa dari ke dua lokasi tempat pengambilan sampel, mangrove yang ditemukan merupakan spesies jenis Avicennia Marina dan Sonneratia alba. Dari ke dua lokasi pengambilan sampel, daerah bahowo memiliki dua spesies A. marina dan S.alba, daerah Talawaan yang memiliki dua spesies A. marina dan $S$. alba.

Dapat dilihat perbandingan konsentrasi $\mathrm{Pb}$ pada kedua sepsies dilokasi Desa Bahowo dan Desa Talawaan bajo. Pada lokasi desa bahowo mangrove jenis $A$. marina konsentrasi $\mathrm{Pb}$ sebesar (0.0435 ppm) dan (0.0148 ppm), pada lokasi Desa Talawaan Bajo mangrove kosentrasi $\mathrm{Pb}$ yang diserap sebesar (0.0134 ppm) dan (0.0013 ppm). Sedangkan untuk konsentrasi $\mathrm{Pb}$ pada spesies $S$. Alba pada Desa Bahowo konsentrasi $\mathrm{Pb}$ sebesar (0.0022 ppm) dan (0.0019 ppm) dan pada Desa Talawaan Bajo memiliki konsentrasi $\mathrm{Pb}$ sebesar (0.0025 ppm) dan (0.0016 ppm). Konsentrasi $\mathrm{Pb}$ yang berada di Desa Bahowo lebih tingi dibandingkan konsentrasi Pb di Desa Talawaan Bajo. Dapat dilihat juga perbandingan dari kedua spesies bahwa mangrove jenis A. marina memiliki kemampuan menyerap logam berat $\mathrm{Pb}$ lebih baik dibandingkan jenis $S$. alba.

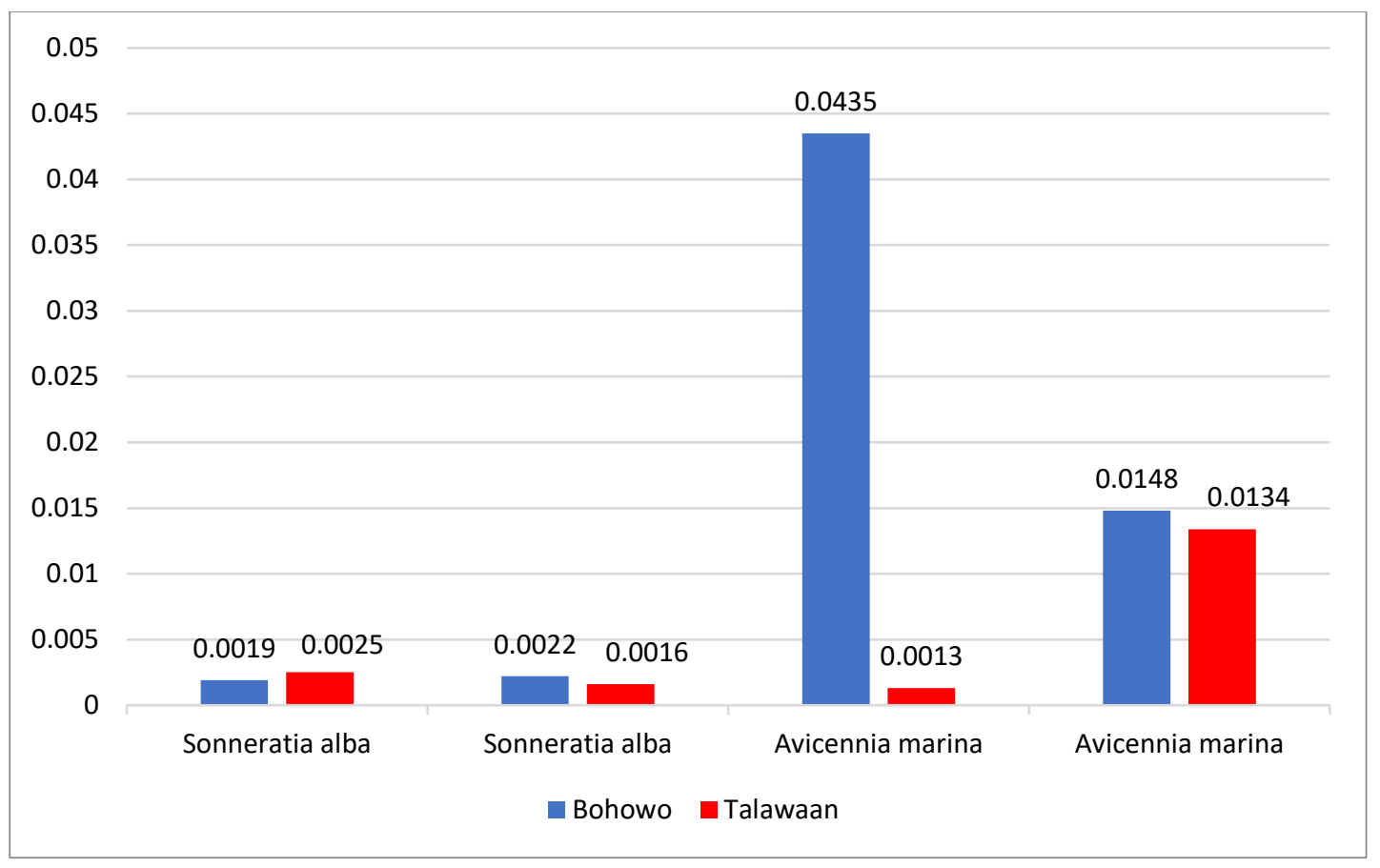

Gambar 6. Grafik kandungan Pb pada Desa Bahowo dan Desa Talawaan Bajo. 
Logam bertat $\mathrm{Pb}$ merupakan logam berat yang termasuk ke dalam jenis logam berat yang berbahaya bagi manusia jika ikut terkonsumsi lewat makanan atau minuman yang dikonsumsi, logam berat $\mathrm{Pb}$ juga sangat berbahaya jika masuk kedalam lingkungan secara berlebihan karena dapat mencemari dan merusak lingkungan, dimana logam berat berbahaya bagi biota dan tumbuhan dalam suatu lingkungan. Keberadaan logam berat timbal dalam di alamada secara alami dan berada pada standar baku mutu lingkungan namu akibat aktivitas manusia menyibabkan timbal lebih banyak masuk ke alam, sama seperti logam berat masuk ke alam disebabkan aktivitas manusia seperti pembuangan limbah dari industri (Setiabudi, 2005).

Logam berat timbal sebagian besar terakumulasi pada organ tanaman yaitu daun, batang dan akar. Perpindahan $\mathrm{Pb}$ dari tanah ke tanaman tergantung pada komposisi dan $\mathrm{pH}$ tanah serta kapasitas tukar kationnya (KTK). Tanaman akan dapat menyerap logam $\mathrm{Pb}$ pada saat kondisi kesuburan tanah dan kandungan bahan organik yang rendah serta KTK tanah tinggi. Mobilitas timbal di dalam tanah dan tumbuhan cenderung lambat dengan memiliki kadar normalnya, kadar normal logam berat $\mathrm{Pb}$ pada tumbuhan berkisar 0,5- 3 ppm (Charlena, 2004).

Hasil ekstraksi sampel yang telah dilakukan pada akar mangrove jenis $A$. Marina dan $S$. alba di daerah Bahowo dan Talawan Bajo memiliki struktur akar yang berbeda per spesiesnya masing-masing. Dari spesies yang ditemukan ada yang memiliki struktur akar keras dan ada juga spesies yang memiliki akar yang agak lunak. Dari hasil analisis logam $\mathrm{Pb}$ megunakan AAS dengan teknik pembakaran suhu tinggi (Graphit Furnace) tumbuhan mangrove $A$. Marina dan $S$. alba pada daerah Bahowo dan Talawaan bajo memiliki kempuan menyerap logam berat $\mathrm{Pb}$. pada analisis ini dapat dlihat kempuan menyerap logam berat setiap spesiesnya berbeda.

Dari uji yang dilakukan dapat dilihat pasa grafik dan tabel bahwa mangrove jenis $A$. marina pada lokasi Desa Bahowo menyerap logam berat $\mathrm{Pb}$ lebih besar dari, memiliki konsentrasi sebesar (0.0435 ppm) dan $(0.0148$ ppm). Jenis $S$. alba konsentrasinya sebesar $(0,0022 \mathrm{ppm})$ dan (0.019 ppm). Pada Desa Talawaan Bajo Jenis $A$. marina menyerap $\mathrm{Pb}$ (0.0134 ppm) dan (0,0013 ppm). Jenis S. alba konsentrasinya sebesar $(0.0025$ ppm) dan (0.0016 ppm).

Tabel 2. Penyerapan Pb setiap spesies dan standar baku mutu pada tumbuhan.

\begin{tabular}{lccc}
\hline NO & Sampel/Lokasi & $\begin{array}{c}\text { Kadar Pb } \\
(\mathrm{ppm})\end{array}$ & $\begin{array}{c}\text { Standar } \mathrm{Pb} \\
\text { Tumbuhan } \\
(\mathrm{ppm})\end{array}$ \\
$\begin{array}{l}\text { dalam Charlena } \\
(2004) .\end{array}$ \\
\hline 2. & $\begin{array}{c}\text { Sonneratia alba } \\
\text { (Bahowo) }\end{array}$ & $\begin{array}{c}(0,0022 \mathrm{ppm}) \\
(0.019 \mathrm{ppm})\end{array}$ & $0,5-3$ \\
3. & $\begin{array}{c}\text { Avicennia marina } \\
\text { (Bahowo) }\end{array}$ & $\begin{array}{c}(0.0435 \mathrm{ppm}) \\
(0.0148 \mathrm{ppm})\end{array}$ & $0,5-3$ \\
4. & $\begin{array}{c}\text { Sonneratia alba } \\
\text { (Talawaan) }\end{array}$ & $\begin{array}{c}(0.0134 \mathrm{ppm}) \\
(0,0013 \mathrm{ppm})\end{array}$ & $0,5-3$ \\
& $\begin{array}{c}\text { Avivennia marina } \\
\text { (Talawaan) }\end{array}$ & $(0.0025 \mathrm{ppm})$ & $0,5-3$ \\
\hline
\end{tabular}


Uji Coba analisis sampel logam berat pada akar mangrove pernah di lakukan Sugiyanto (2016) di pesisir Probolinggo, Jawa Timur. mangrove A. marina memiliki konsentrasi logam berat $\mathrm{Pb}$ sebesar $(0.008 \mathrm{ppm})$ dan $\mathrm{Hg}$ sebesar $(0,1401 \mathrm{ppm})$, begitu juga pada analisis logam berat $\mathrm{Pb}$ oleh Jupriyati (2013) di Mangunharjo Semarang, hasil uji coba yang dilakukan pada mangrove A.Marina pada lokasi Desa Bahowo konsentrasi daya serap logam berat $\mathrm{Pb}$ paling tinggi sebesar (0.0435) dan desa talawaan bajo sebesar (0.0134 ppm). Pada lokasi desa Bahowo jenis $S$. alba $(0.0022$ ppm) dan Desa Talawaan Bajo (0.0025 ppm). Dilihat dari berapa kajian yang pernah di lakukan di daerah pesisir Probolinggo dan perairan Mangunharjo Semarang kandungan logam berat $\mathrm{Pb}$ di daerah Bahowo dan Talawaan Bajo memiliki konsentrasi yang lebih besar.

Perbedaan akumulasi dari tiap setasiun penelitian dikarenakan perbedaan jenis mangrove yang tumbuh pada kedua setasiun penelitian. Perbedaan ini dimungkinkan juga karena morfologi akar $S$. alba yang berbeda dengan $A$. marina. Kemampuan akumulasi logam berat tersebut berbeda untuk tiap spesies. Tumbuhan mangrove mengakumulasi logam berat paling tinggi terdapat di bagian akarnya. Namun demikian faktor lain seperti mobilitas dan kelarutan logam juga berpengaruh terhadap akumulasi logam berat dalam tumbuhan (Tam and Wong, 1996)

Mulyadi et al., (2009) dalam penelitiannya memperoleh hasil bahwa akar pohon api-api $A$. marina dapat mengakumulasi tembaga ( $\mathrm{Cu}$ ). Selain akumulasi, diduga $A$. marina ini memiliki kemampuan penanggulangan toksik lain, diantaranya dengan melemahkan efek racun melalui pengenceran (dilusi), yaitu dengan menyimpan banyak air untuk mengencerkan konsentrasi logam berat dalam jaringan tubuhnya sehingga dapat mengurangi toksisitas logam tersebut. Pengenceran dengan penyimpanan air di dalam jaringan biasanya terjadi pada daun dan diikuti dengan terjadinya penebalan daun (sukulensi). Ekskresi juga merupakan upaya yang mungkin terjadi, yaitu dengan menyimpan materi toksik logam berat didalam jaringan yang sudah tua seperti daun tua dan kulit batang yang mudah mengelupas, sehingga dapat mengurangi konsentrasi logam berat di dalam tubuhnya.

\section{KESIMPULAN}

Berdasakan penelitian yang telah dilakukan dapat disimpulkan bahwa:

1. Tumbuhan mangrove jenis $A$. Marina dan $S$. alba memiliki kemampuan sebagai biofilter menyerap logam berat di perairan.

2. Setiap jenis mangrove memiliki kemampuan menyerap logam berat berbeda-beda.

3. konsentrasi $\mathrm{Pb}$ yang berada di daerah Bahowo lebih tinggi dibandingkan konsentrasi $\mathrm{Pb}$ di daerah Talawaan Bajo.

\section{UCAPAN TERIMA KASIH}

Penulis mengucapkan Program Demand-Driven Research COREMAPCTI dan Pusat Penelitian Oseanografi LIPI, tahun 2018 yang melibatkan dan mendanai penelitian ini.

\section{DAFTAR PUSTAKA}

Bahri, S. 2010. Lead Firoremediation $(\mathrm{Pb})$ in Water Contaminated by Great Duckweed Water Plant (Spirodela polyrhiza). Journal of Hydraulic Engineering, 1(2):95192

Charlena. 2004. Pencemaran Logam Berat Timbal $(\mathrm{Pb})$ dan Cadmium (Cd) pada Sayur-sayuran. Http://www.rudyct.com/PPS702pb/09145/charlena.pdf. diakses tanggal 11 Januari 2018. 
Crawford R, Crawford D.L. 1996 Bioremdiation Principles and Applications. Cambridge: Cambridge University Pr.

Dahuri, 2003. Profil Ekosistem Mangrove Di Desa Bahoi Kabupaten Minahasa Utara. Jurnal IImiah Platax. ISSN: 23023589. 3:(2) : 140-188.

Gunarto. 2004. Konservasi Mangrove Sebagai Pendukung Sumber Hayati Perikanan Pantai. Jurnal Litbang Pertanian, 23(1) : 102130.

Hastuti , E. D., Anggoro S., Pribadi R. 2013. Pengaruh Jenis dan Kerapatan Vegetasi Mangrove terhadap Kandungan $\mathrm{Cd}$ dan $\mathrm{Cr}$ Sedimen di Wilayah Pesisir Semarang dan Demak, Prosiding Seminar Nasional Pengelolaan Sumber daya Alam dan Lingkungan.

MacFarlane, G.R., M.D. Burchett. 2000. Cellular Distribution of Copper, Lead and Zinc in the Grey Mangrove, Avicennia marina (Forsk.) Vierh. Aquatic Botany 68:45-59.

Mulyadi, E., Laksmono, R., Aprianti, D. 2009. Fungsi Mangrove Sebagai Pengendali Pencemar Logam Berat. Jurnal IImiah Teknik Lingkungan 1: 33-39.

Nybakken, J.W.1988. Marine Biology: An Ecological Approach. PT. Gramedia,Jakarta.

Jupriyati, R. 2013. Akumulasi Logam Berat Timbal $(\mathrm{Pb})$ dan Pengaruhnya Terhadap Histologi Akar Mangrove Avicennia marina (Forssk). Vierh. di Perairan Mangunharjo Semarang. Journal of Marine Research 3: 361-68.

Seanger. 1983. Global Status of Mangrove eEkosistem, IUCN Commission on Ecology Papers, No 3. 1998.
Schaduw, J.N.W. 2015. Keberlanjutan Pengelolaan Ekosistem Mangrove Pulau Mantehage, Kecamatan Wori, Kabupaten Minahasa Utara Provinsi Sulawesi Utara. Jurnal LPPM Bidang Sains dan Teknologi. Universitas Sam Ratulangi. 2 (2) : 156-201.

Setiabudi, B. T., 2005. Penyebaran Merkuri Akibat Usaha Pertambangan Emas di Daerah Sangon, Kabupaten Kulon Progo, D.I. Yogyakarta.

Sugiyanto, N. 2016. Analisis Akumulasi Logam berat Timbal $(\mathrm{Pb})$ dan Kadmium (Cd) pada Akar Mangrove sebagai agen fitoremediasi di pesisir Probolinggo, Jawa Timur.

Tam , N.F.Y. 1997. Normalisation And Heavy Metal Contamination In Mangrove. The Science of The Total Environment 216 : 33-39.

Tam, N.N.F.Y., Wong, Y.S.. 1996. Retention and Distribution of Heavy Metals in Mangrove Soils Receiving Wastewater. Environmental Pollution, 94 (3) : 283-291 